\title{
Authentic Leadership Influenced on the Acceptability of Information and Communication Technology for School Management
}

\author{
Daryanto $^{1}$, Taryudi², J D Ticoh ${ }^{2}$ \\ ${ }^{1,2}$ Faculty of Engineering, Universitas Negeri Jakarta, Indonesia \\ ${ }^{3}$ Faculty of Engineering, Universitas Negeri Manado, Indonesia \\ corresponding author: ${ }^{1}$ daryanto@unj.ac.id
}

\begin{abstract}
Authentic leadership and school culture are essential factors influenced the acceptability of information and communication technology (ICT) for school management. This study aims to determine the effect of authentic leadership on the acceptance of ICT for school management. This study was conducted using a casual survey with proportional random sampling technique. A total 191 respondents were agreed to join in this study. Data were analyzed using path analysis with Partial Least Square (PLS) approach. The results of this study showed that authentic leadership has a positive and significant impact on ICT acceptance. In conclusion, authentic leadership influenced directly and indirectly perceptions of ICT use, easy use, attitude to use, and actual ICT.
\end{abstract}

\section{Introduction}

Management of the vocational high school is a challenging job because their management is very different from general high School. The curriculum must be well managed; the expensive equipment needs to be used optimally and routinely maintained, and well arrangement of learning schedule in classrooms, laboratories, and industry. They also need to have good cooperation with industry, provide much networking for a graduate to have more opportunity working in the business and industry sector, and well-managed for alumni tracking system. In addition to the regulation of staff development is necessary to improve competence in managing vocational education. School management is a process of utilizing all school resources through rational and systematic action, planning, organizing, and control to achieve an effective and efficient of school objectives. To support the implementation of school management required the application of technology, especially information and communication technology (ICT). Utilization of ICT in schools aims to improve service to stakeholders especially students which the ultimate aims are to enhance the quality of graduates both academic and nonacademic. Technology will mean nothing if it is not used to 
support human work. The success of ICT utilization is determined by technology itself and the organizational factors. Technological factors related to the completeness of hardware and software, while the organizational factors include attitudes and competence of technology users, organizational culture, leadership, and other factors. The role of ICT in school management serves as a tool to support organizational performance. Therefore the usefulness of ICT for management depends on the human resources.

According to Roger (1983: 24), the process of acceptability technology is influenced by the social system in which the diffusion process takes place. The structure of communication networks in a social system has an essential influence in the diffusion process, as well as values and culture in the system and various roles such as leaders opinion, influential people on others attitudes and behaviors. This leader's view is a key figure in the diffusion process both management and worker levels. The utilization of digital technology in schools a showed a significant impact on the role and responsibilities of school leaders. ICTs have called for a systematic change in schools. Unavoidably, school leaders and teachers were in under pressure situation to make a lot of effort to implement and promote technological innovation. Teachers are central to adopt, however, the impact usability, and benefit on the learning process and education system would depend on utilization of the technology. The same technology applied in different people would produce a different result. The acceptability of ICT is not a technical issue but more than a continuing learning process.

The used of ICTs in school management have an essential role in the school leadership development. Anderson \& Dexter (2000, pp. 79) emphasized that leadership-oriented technology in schools was influenced by the existing of technology committees, government funding support, leader email, the time to pursue technology, staff, intellectual property policies, and other policies. Nevertheless, the use of ICT for school management is more focused on the fulfillment of its infrastructure, not considering user behavior and organizational factors yet, mainly related to authentic leadership. Therefore, this study aims to determine the effect of authentic leadership on the acceptability of ICT for school management.

\section{Methods}

This study was conducted using a casual survey with path analysis approach. The target population in this study was a school leader, school committee, teacher, and academic staff in one of public vocational high education in West Java. The total target population was 369. Proportional Random Sampling was applied to the selected participant, and total 191 sample was recruited 
Journal of Educational Method and Technology Vol. 1 No. 2, September 2018

P-ISSN 2622-8459 E-ISSN 2622-8467

http://ejournal.unima.ac.id/index.php/jemtec

according to Slovin formula. Data were analyzed using path analysis with Partial Least Square (PLS) as an alternative to structural equation modeling (SEM)..

\section{Results and Discussion}

The path coefficient of authentic leadership effects' on acceptability TIC shows a below in Table 1

Tabel 1. Path coefficient between variables

\begin{tabular}{lccccc}
\hline & $\begin{array}{c}\text { Original } \\
\text { Sample } \\
(\mathbf{O})\end{array}$ & $\begin{array}{c}\text { Sample } \\
\text { Mean } \\
(\mathbf{M})\end{array}$ & $\begin{array}{c}\text { Standard } \\
\text { Deviation } \\
(\text { STDEV })\end{array}$ & $\begin{array}{c}\text { T Statistics } \\
(|\mathbf{O} / \mathbf{S T D E}|)\end{array}$ & $\begin{array}{c}\text { P } \\
\text { Values }\end{array}$ \\
\hline $\begin{array}{l}\text { AL -> } \\
\text { ACTU }\end{array}$ & 0.624 & 0.627 & 0.055 & 11.335 & 0.000 \\
AL -> PEU & 0.496 & 0.498 & 0.061 & 8.093 & 0.000 \\
AL -> PU & 0.411 & 0.412 & 0.074 & 5.574 & 0.000 \\
ATU -> & 0.303 & 0.300 & 0.066 & 4.586 & 0.000 \\
ACTU & & & & & \\
PEU -> & 0.298 & 0.303 & 0.075 & 3.976 & 0.000 \\
ATU & 0.427 & 0.425 & 0.074 & 5.737 & 0.000 \\
PEU -> PU & 0.585 & 0.583 & 0.072 & 8.141 & 0.000 \\
PU -> ATU & 0.58
\end{tabular}

In the final model, relationship between authentic leadership (AL) with acceptability of TIC (perception of TIC use (PU), perception of easly use of TIC (PEU), attitude toward TIC (ATU), actual used of TIC (ACTU)) are shown in Figure 1 as below. 


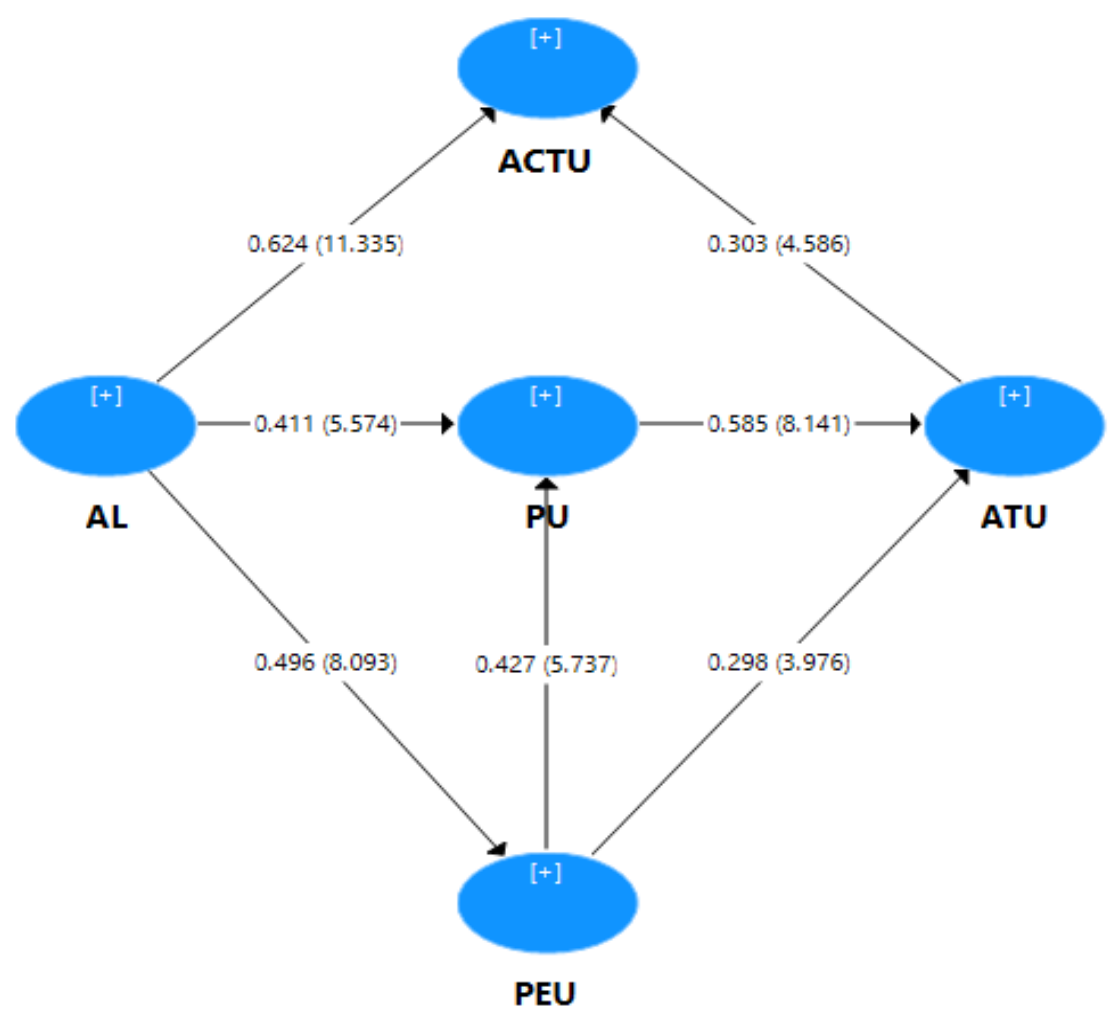

Figure 1. Coefficient path analysis of AL towards the acceptability of TIC

\subsection{Authentic leadership towards the perception of TIC use}

The results showed that coefficient path analysis of authentic leadership towards the perception of TIC use was $0.411, \mathrm{~T}=5.574$ bigger than $\mathrm{T}$ table 1.96 in the $\mathrm{p}$-value $=0.05$ (2-tailed). This study showed that authentic leadership had a $16.93 \%$ significant impact on the perception of TIC use. The previous study supported that authentic leadership is a lifelong development phenomenon to gain greater self-awareness with a strong commitment to self-regulation (Chang et al. 2005, page. 35). The leader needs to challenge himself throughout his life, as ICT will continue to develop and require learning continuously. Avolio dan Gardner (2005, page. 232) stated that the focus of authentic leadership is personal development before one gets or achieves its leadership role. It is one of the distinctive features of authentic leadership from other leaders. Although people have achieved authentic leadership, it does not necessarily finish to learn, constantly an authentic leader will continue to develop his personality to become a better authentic leader.

\subsection{Authentic leadership towards the perception of easily use of TIC}

The results showed that coefficient path analysis of authentic leadership towards the perception of easily use of TIC use was $0.496, \mathrm{~T}=8.093$ bigger than $\mathrm{T}$ 
table 1.96 in the p-value $=0.05$ (2-tailed). This study showed that authentic leadership had a $24.62 \%$ significant impact on the perception of easily use TIC use and about $75.38 \%$ due to other factors. Authentic leadership has an influence on the perception of convenience in the use of ICT as stated by Bill George's (2003, p.18) emphasized that authentic leadership is a type of leadership that promotes self-awareness above other dimensions. Furthermore, Bill George (in Northouse, 2013, page. 258) found that authentic leaders have a genuine desire to serve others, they know themselves, and they feel free to lead from their core values. The perception of ease of use is defined as the degree to which a person believes that using a particular system will be free of physical and mental effort. Efforts to improve the perception of easily of technology is warranted. The first factor related to the technology itself is usually associated with the experience, therefore, providing user-friendly technology and intensive use training is important. The second factor is the poor reputation of technology as known by the user. Some effort can be done to improve it such as bring the technology to the user and allow users to interact with the technology. The third factor is the support mechanism. The solution to this problem is to provide support teams that can assist at any time and offer usage guides that can be accessed at any time as user needed. Based on this, it has become the task of a leader to guide staff in improving their willingness and mindset in the perception of ease of use of ICT.

\subsection{Authentic leadership towards the perception of the actual use of TIC}

The results showed that coefficient path analysis of authentic leadership towards the perception of the actual use of TIC use was $0.624, \mathrm{~T}=11.33$ bigger than $\mathrm{T}$ table 1.96 in the $\mathrm{p}$-value $=0.05$ (2-tailed). This study showed that authentic leadership had a $38.99 \%$ significant impact on the perception of actual use TIC use and about $61.01 \%$ due to other factors. Authentic leadership influences the use of ICT which brings many changes in our attitude and act both individually and as a member of an organization. The change not only in the work of a leader, structure, authority, power but also on the content of the work itself. Actual system usage is the real condition of system usage. In the context of the use of information technology systems, the behavior is conceptualized in practical use which is a form of measurement of the frequency and duration of technology usage. In other words, actual usage is measured as the amount of time spent interacting with technology and its frequency of use. People will be intensively to use the system if it believes that the system is easy to use and will increase its productivity as reflected in the real conditions of its use.

\subsection{Easy use of ICT toward the perception of ICT use}


The results showed that coefficient path analysis of the easy use of ICT toward the perception of ICT use was $0.298, \mathrm{~T}=3.976$ bigger than $\mathrm{T}$ table 1.96 in the $\mathrm{p}$-value $=0.05$ (2-tailed). This study showed that perception of easily use of TIC had an $8.86 \%$ significant impact on the perception of actual use TIC use and about $65.79 \%$ due to other factors. The results of this study support the theory that the perception of ease in use affects attitudes to use for individuals towards the use of technology. The increase in perceived ease of use influences the increase of perceived usefulness because an easy-to-use system does not take long time to learn so that the individual has an opportunity to do something else, it is related to performance effectiveness (Davis, Bagozzi and Warshaw, 1989: 987).

\subsection{The perception the usage of TIC towards an attitude of TIC use}

The results showed that coefficient path analysis of the perception useful of ICT toward the ICT use was $0.485, \mathrm{~T}=8.141$ bigger than $\mathrm{T}$ table 1.96 in the $\mathrm{p}$ value $=0.05$ (2-tailed). This study showed that authentic leadership has a $34.21 \%$ significant impact on the attitude of TIC use and about $65.79 \%$ due to other factors. Human is the used of the system who psychologically has a specific behavior thus the aspects of behavior in the human as the ICT (brain ware) user becomes an essential determinant factor. According to Syam (1999), consideration of this behavior needs particular attention in the context of ICT application. Technical factors, behaviors, situations and ICT user personnel need to be considered before ICTs are implemented. Similarly, user behavior and personal systems are needed in systems development, and this is related to the understanding of the system. Thus it can be concluded that the perception of the personnel involved in the implementation of the system will affect the end of a system, whether the system is successful or not, acceptable or not, useful or not if applied. It's supported by some theoretical descriptions and empirical research. The behavior in the application of ICT is one crucial aspect because it is directly related to the user. The interaction between users with computer devices is influenced by the perception, attitude, affection as the aspect of behavior. In conclusion, the application of a system, and information technology is embedded with human behavior because of the development of systems related to individual and organizational problems as users of the system. Thefeore, the system developed must be oriented to the users.

\subsection{The attitude of TIC use towards the application of TIC}

The path coefficient of TIC use toward the implementation of TIC was $0.303, \mathrm{~T}=4.586$ bigger than $\mathrm{T}$ table 1.96 in the $\mathrm{p}$-value $=0.05$ (2-tailed). This study showed that attitude has a $9.12 \%$ significant impact on the application of TIC use and about $91.88 \%$ due to other factors. Attitudes to using ICTs are a form of a 
Journal of Educational Method and Technology Vol. 1 No. 2, September 2018

P-ISSN 2622-8459 E-ISSN 2622-8467

http://ejournal.unima.ac.id/index.php/jemtec

person's belief in using actual ICTs. Attitudes to using ICT encourage a person to behave in using ICT. This refers to school staff who have an attitude in using ICT. The ease and usefulness of the technology will encourage school staff to continue to maintain its use both in work and daily life and will ultimately provide a sense of satisfaction as it can accelerate and speed up task completion.

\subsection{Easy use of ICT toward the perception of ICT usefulness}

The path coefficient of easy use of ICT toward the perception of ICT usefulness was $0.427, \mathrm{~T}=5.737$ bigger than $\mathrm{T}$ table 1.96 in the $\mathrm{p}$-value $=0.05(2$ tailed). This study showed that easy use of ICT has an $18.21 \%$ significant impact the perception of ICT usefulness and about $81.79 \%$ due to other factors. Davis, F.D (1989) defines ease of use as a level where one believes that a computer can be easily understood. According to Goodwin (1987); Silver (1988); in Adam, et al (1990), the intensity of use and interaction between users with the system can also indicate the ease of use. The more frequently used systems would resulted to better known, easier to operate and easier to use. Based on the above definition, it can be concluded that ease of use will reduce the effort (both time and energy) a person in learning the computer. There were differences in using ICT while work, they feel more efficiently to work than people without using ICT. Characteristic of ease of use ICT was believe that ICT is more flexible, easy to understand and easy to operate. Davis further provides several indicators of ease of use of ICTs including; (1) The computer is easy to learn, (2) The computer meet user needs (3) The user's skill increases by using the computer (4) The computer is very easy to operate. Iqbaria (1994) reported that the acceptance of the use of microcomputer is affected by the ease of use or social pressure. However, the ICTs used are not absolute because of social pressure, but more because it is easy to use. In conclusion, the acceptance of ICT use is influenced by the ease of use of ICT, it's showed a psychological reflection of users who are more open to something. Convenience on using ICT can encourage a person to use ICT.

\section{Conclusion}

1. Authentic leadership directly influenced perceptions of ICT use, perceived ease of using ICTs, and actual use of ICTs, and indirectly influences actual ICT usage.

2. The perception of easily use ICTs influenced perceptions of ICT use and attitudes to use ICTs, as well as indirectly affect actual ICT use.

3. Perceptions of ICT used affect the attitude to use ICT and indirectly affect the actual use of ICT.

4. Attitudes to using ICTs directly affect the actual use of ICTs. 
Journal of Educational Method and Technology Vol. 1 No. 2, September 2018

P-ISSN 2622-8459 E-ISSN 2622-8467

http://ejournal.unima.ac.id/index.php/jemtec

\section{References}

[1] Anderson RE, Dexter S. School technology leadership: An empirical investigation of prevalence and effect. Educational Administration Quarterly. 2005 Feb;41(1):49-82.

[2] Arvil Van Adams, dkk. (1990). Skills Training For Productivity Strategies for Improved Efficiency in Developing Countries. Manila: Asian Development Bank.

[3] Chang V, David B, Wills G, De Roure D, (2010). "A Categorisation of Cloud Business Models", CCGrid, 10th International Symposium on Cluster, Cloud and Grid Computing, May 2010, Melbourne, Australia. 